International Journal of Engineering \& Technology, $7(2.12)(2018) 301-303$
International Journal of Engineering \& Technology
SPC
Website: www.sciencepubco.com/index.php/IJET
Research Paper

\title{
A Study on characteristics improvement of concentrated flux IPM BLDC motor using the flared-shape rotor Structure with Ferrite Magnets
}

\author{
Keun-Young Yoon * \\ Department of Electrical Engineering, Honam University, 417 Eodeung-daero Gwangju-si, South Korea \\ *Corresponding author E-mail: ky.yoon@honam.ac.kr
}

\begin{abstract}
Background/Objectives: This paper proposes the alternative possibilities that the flared-shape rotor structure of IPM BLDC motor has the similar high performances as the basic IPM BLDC motor that has the spoke structure with ferrite magnet.

Methods/Statistical analysis: The proposed rotor structure has the structural feature of ferrite magnets which has inserted as the flared shape in the rotor core. Through the finite element analysis, the performances of the proposed flared-shape IPM BLDC motor has compared with the basic spoke type IPM BLDC motor.

Findings: This paper show the comparison with the analysis results of 2D FEM and it has shown that the proposed IPM motor has a substitute for the spoke type IPM motor which requires low cost and high output power. Especially the proposed flared IPM motor has a low pulsation of torque than the basic type IPM motor. So the proposed flared IPM motor has the advantage for acoustic noise and vibration the spoke type IPM motor.
\end{abstract}

Improvements/Applications: The proposed flared-shape IPM BLDC motor is suitable for as electric vehicle and home appliances motor.

Keywords: Interior Permanent Magnet (IPM); Ferrite Magnet; Brushless DC; Flared-Shape

\section{Introduction}

The BLDC motors is widely used in the automotive industries (electrical vehicles) and domestic appliance industries. The IPM BLDC motors that are made by inserting permanent magnets into rotors have advantages for applications requiring high output power and high efficiency at load condition 1,2,3,4. Especially The IPM motors have saliency depending on rotor shape. Therefore reluctance torque components can be obtained in addition to the magnetic torque components. So the total torque amount of IPM BLDC motors is higher than that of surface permanent magnet (SPM) motors which only contains magnet torque 5, 6, 7, 8, 9. In this study, we will compare the characteristics of the basic IPM model (the spoke structure) and the proposed flared type IPM model (the flared structure). The flared type IPM model adopts a flared structure of $\mathrm{C}$-shape ferrite magnets that are placed in the shape of flared form. The proposed flared- shape structure can improve to increase the useful magnetic flux 10. Hence, the characteristics of the proposed flared-shape IPM BLDC model can be improved compared the existing performance of basic model.

\section{Structures of spoke type IPM model and flared type IPM model}

\subsection{Basic spoke type ferrite IPM model}

The multi-polar structure of IPM model and the concentrated winding has a high output power density per unit volume and high efficiency so it has been widely used in fields such as home appli- ances and electric vehicle and Fig. 1 shows a shape of the basic spoke type ferrite IPM model and a permanent magnet is magnetized in a concentrated flux structure (yellow mark). The basic spoke type ferrite IPM model is applied with concentrated winding and 12 slots $(\mathrm{S}) / 8$ poles $(\mathrm{P})$. In order to prevent the problem of scattering in a high-speed rotation, rotor structure is designed in interior permanent magnet rotor structure and composed of plastic resin and it is advantageous with a high speed rotating. Moreover, the basic spoke type ferrite IPM model is used the ferrite magnets as $9 \mathrm{BE}$ grade with low cost than the $\mathrm{NdFeB}$ magnet.

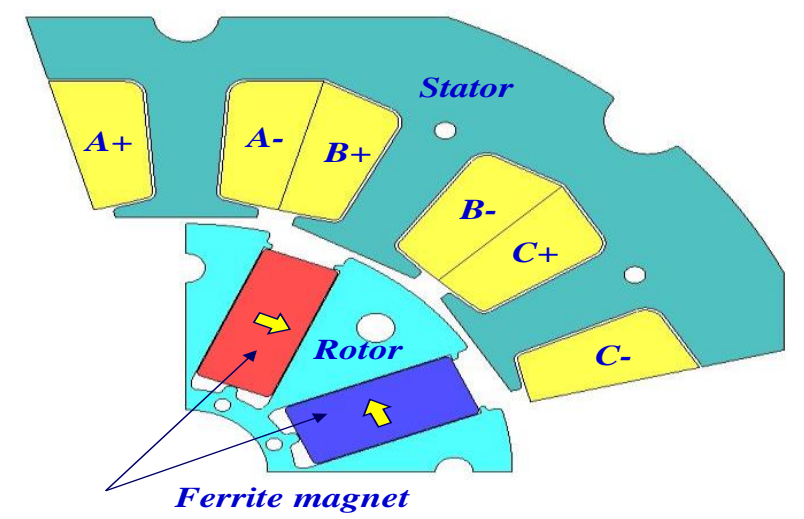

Fig. 1: Structure of Conventional Spoke Type Ferrite IPM Model (1/4model). 


\subsection{Proposed flared ferrite IPM model}

Figure 2 shows the structure of proposed flared-shape IPM model which has 12Slots/8Poles and concentrated winding. The proposed flared-shape structure has a several C-shaped ferrite magnets arranged in the flared shape form in the rotor. The flaredshape structure of ferrite magnets can increase the usage of the ferrite magnets in the rotor core as much as possible. So the proposed flared type structure can obtain the concentration effect of magnetic flux which is caused by the flared-shape arrangement of $\mathrm{C}$-shaped ferrite magnets

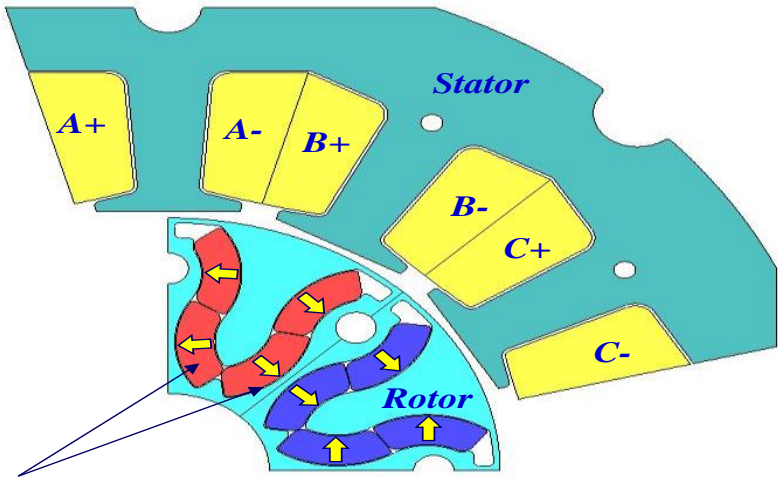

Ferrite magnet

Fig. 2: Structure of Proposed Flared Ferrite IPM Model (1/4model).

Figure 3 shows the magnetization pattern of proposed flared ferrite IPM model. The proposed flared model can have two patterns of parallel and radial direction. In this paper, we applied the radial direction of the magnetization pattern and one polarity formed by using four $\mathrm{C}$-shaped type ferrite magnets.
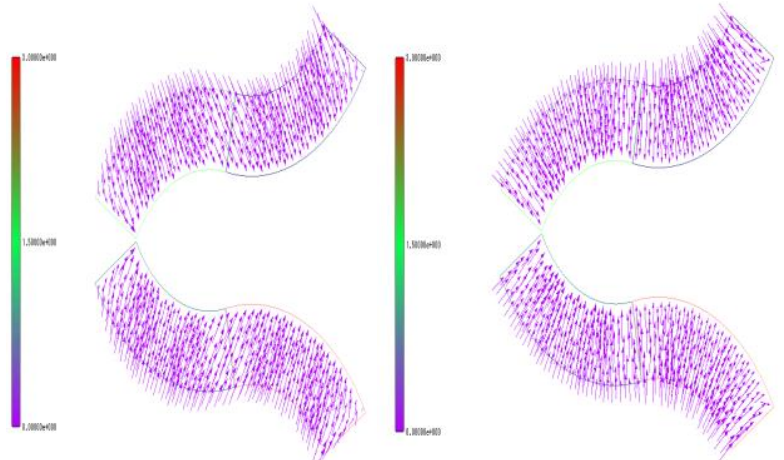

Fig. 3: The Magnetization Direction of Proposed Flared Ferrite IPM Model.

\subsection{Comparison of the specifications with basic mode and proposed model}

Table 1 shows the mechanical specifications of the basic IPM model (spoke type) and the proposed flared-shape type IPM model. To compare the performance of the basic spoke type ferrite IPM model, the mechanical volume (stator stack height, stator/rotor diameter and air-gap length) of the proposed flared type ferrite IPM model is the same level as the basic spoke type ferrite IPM model.

Table 1: Specification of Conventional Spoke Model and Proposed Flared Model

\begin{tabular}{|c|c|c|c|c|}
\hline \multicolumn{2}{|l|}{ Item } & Unit & $\begin{array}{l}\text { Conventional } \\
\text { Spoke model }\end{array}$ & $\begin{array}{l}\text { Proposed } \\
\text { Flared model }\end{array}$ \\
\hline \multicolumn{2}{|c|}{ Slot / pole } & - & $12 / 8$ & \\
\hline \multirow{2}{*}{\multicolumn{2}{|c|}{$\begin{array}{l}\text { Output power } \\
\text { Speed }\end{array}$}} & W & 2,500 & \\
\hline & & rpm & 10,005 & \\
\hline \multirow{3}{*}{ Stator } & Stack & $\mathrm{mm}$ & 27.5 & \\
\hline & $\begin{array}{l}\text { Outer/Inner } \\
\text { diameter }\end{array}$ & $\mathrm{mm}$ & $120.0 / 61.5$ & \\
\hline & Material & - & $35 \mathrm{PN} 470$ & \\
\hline
\end{tabular}

\begin{tabular}{|c|c|c|c|c|}
\hline \multirow{4}{*}{ Rotor } & Stack & $\mathrm{mm}$ & 27.5 & \multirow{7}{*}{$\begin{array}{l}\text { C-type } \\
(70 \mathrm{deg} * 3.4 \mathrm{t})\end{array}$} \\
\hline & $\begin{array}{l}\text { Outer diame- } \\
\text { ter }\end{array}$ & $\mathrm{mm}$ & 60.0 & \\
\hline & Air-gap & $\mathrm{mm}$ & 0.75 & \\
\hline & Material & - & $35 \mathrm{PN} 470$ & \\
\hline \multirow[t]{2}{*}{ Magnet } & $\begin{array}{l}\text { Shape } \\
\text { (Size) }\end{array}$ & - & $\begin{array}{l}\text { Bar-type } \\
(16.5 \mathrm{~mm} * 7.4 \mathrm{t})\end{array}$ & \\
\hline & Material & - & Ferrite 9BE & \\
\hline \multirow{2}{*}{ Winding } & Turns & - & $0.9 * 30$ turns & \\
\hline & Material & - & $\mathrm{Cu}$ & \\
\hline
\end{tabular}

\section{Characteristics of spoke type IPM model and flared type IPM model}

\subsection{Characteristics at no-load condition}

The back-EMF at no-load condition are shown in Figure 4. The back-EMF has a different according to the core shape and the structure of magnets. Compared to the basic spoke type IPM model, the flared-shape structure of ferrite magnets has an advantage that the concentration effect of magnetic flux in the central part of the rotor core depending to the arrangement of C-shaped ferrite magnets. Therefore the back-EMF waveform of the proposed flared-type ferrite model in no-load condition is increased by $4.2 \%$ than the basic spoke type ferrite IPM model.

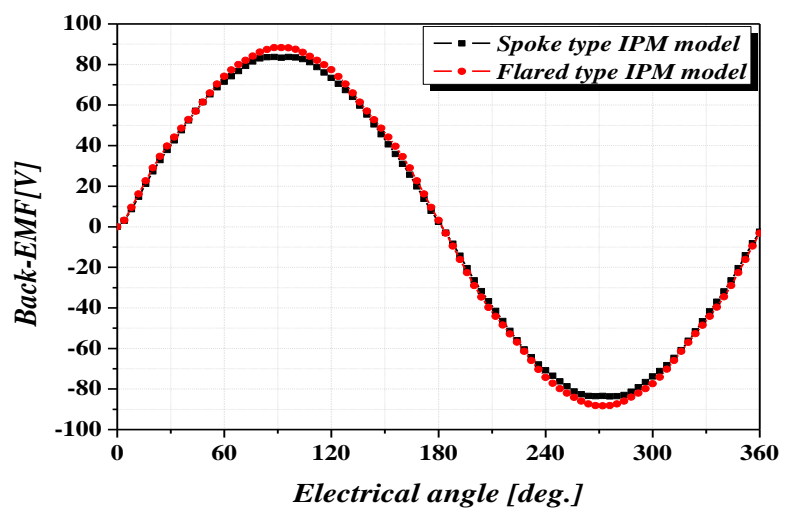

Fig. 4: Characteristics of the No-Load Condition - Back-EMF Waveforms

Figure 5 shows T.H.D (Total Harmonic Distortion) analysis of the back-EMF waveforms. The T.H.D of back-EMF is designed in equivalent level $(2.0 \%)$ with the basic spoke type ferrite IPM model $(1.5 \%)$. In general, the limit of T.H.D is under $3.0 \%$ in consumer electronics and electric vehicle

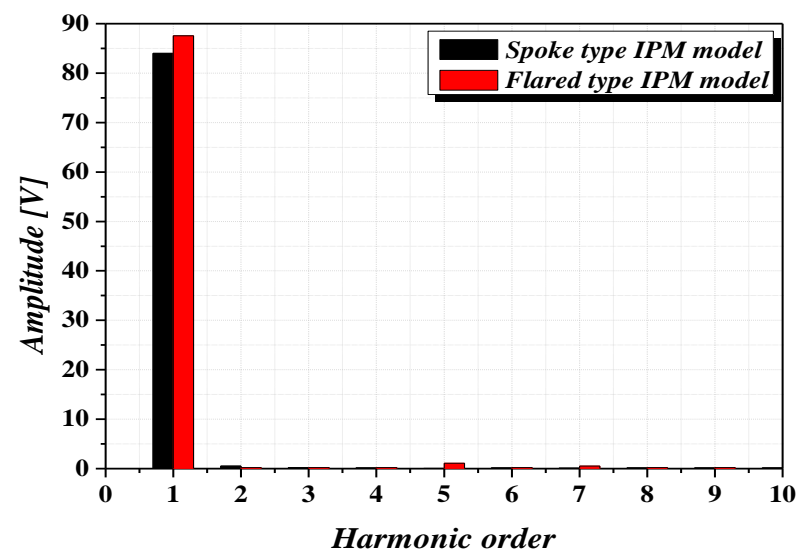

Fig. 5: Characteristics of the No-Load Condition - T.H.D of the BackEMF Waveforms.

Figure 6 shows the cogging torque waveforms at no-load. Although the cogging torque ripple of the proposed flared-shape ferrite IPM model is increased by $36.7 \%$ than the basic IPM model, it represents a smaller ripple waveform than the rated torque waveform. 


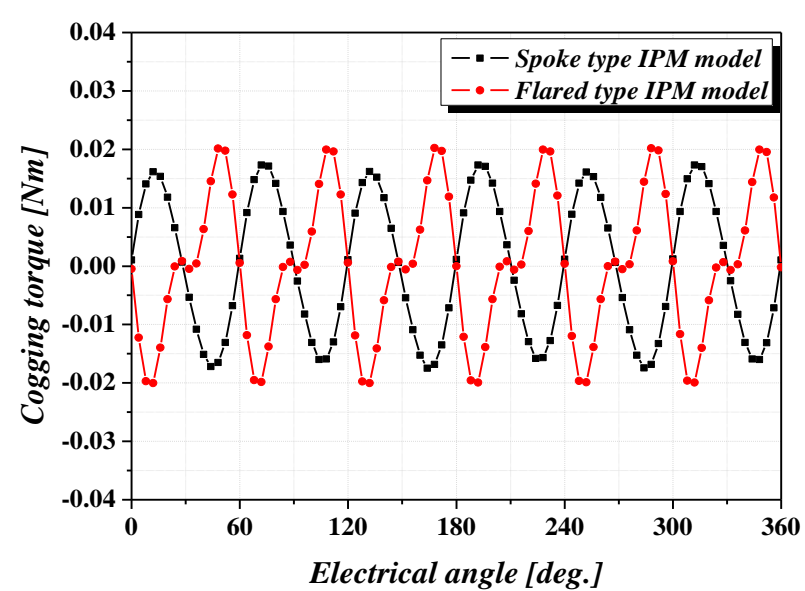

Fig. 6: Characteristics of the No-Load Condition - Cogging Torque Waveforms.

Table 2 shows the 2D FEM analysis results of the proposed flared type IPM model in comparison with the basic spoke type ferrite IPM BLDC model.

Table 2: Comparison of the Characteristics at No-Load

\begin{tabular}{|c|c|c|c|c|c|}
\hline Item & & Unit & $\begin{array}{l}\text { Conventional } \\
\text { Spoke model }\end{array}$ & $\begin{array}{l}\text { Proposed } \\
\text { Flared } \\
\text { model }\end{array}$ & $\begin{array}{l}\text { Change } \\
\text { ratio }\end{array}$ \\
\hline \multirow{3}{*}{$\begin{array}{l}\text { No- } \\
\text { load }\end{array}$} & $\begin{array}{l}\text { Back-EMF } \\
\text { at } 10 \mathrm{krpm}\end{array}$ & Vrms & 59.1 & 61.6 & $\uparrow 4.2 \%$ \\
\hline & T.H.D & $\%$ & 1.5 & 2.0 & - \\
\hline & $\begin{array}{l}\text { Cogging } \\
\text { torque } \\
\text { ripple }\end{array}$ & $\mathrm{mNm}$ & 0.30 & 0.41 & - \\
\hline
\end{tabular}

\subsection{Characteristics at load condition}

Figure seven shows the torque ripple of proposed flared-shape IPM model which compared to the basic ferrite IPM BLDC model (spoke type). As shown in figure 7 , the average torque is equivalent level and the torque ripple is reduced by $30.7 \%$ compared to the basic spoke type ferrite IPM model. So the Improvement of torque ripple at rated load has an advantage to reduce a model noise and vibration. Therefore the proposed flared type IPM model can apply to the field of applications where noise and vibration improvements are demanded.

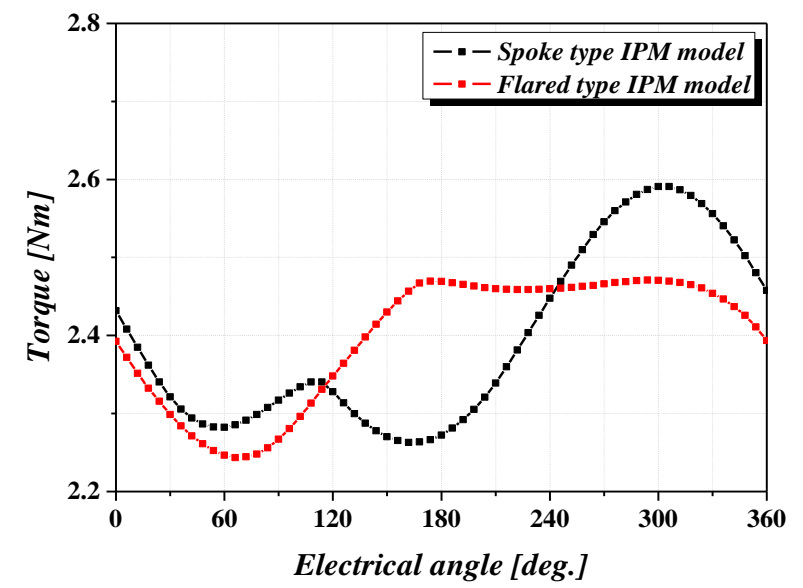

Fig. 7: Characteristics of the Load Condition - Torque Waveforms.

Figure 8 shows the nodal force waveforms that applied to stator teeth. When the nodal force by the electromagnetic force is applied to the stator teeth as exciting forces, it cause noise and vibration at operating point. Especially, the maximum change of the nodal force occurs noise and vibration in the stator teeth. Therefore, the nodal force that applied to stator teeth should be designed to be minimized during the initial design. Figure 9 shows the comparison of the nodal force of the proposed flared type IPM model compared to the basic ferrite IPM model at the operating point, as shown in Fig. 9, the average value of nodal force of the proposed flared-shape IPM model is reduced by $13.4 \%$ compared to the basic IPM model.

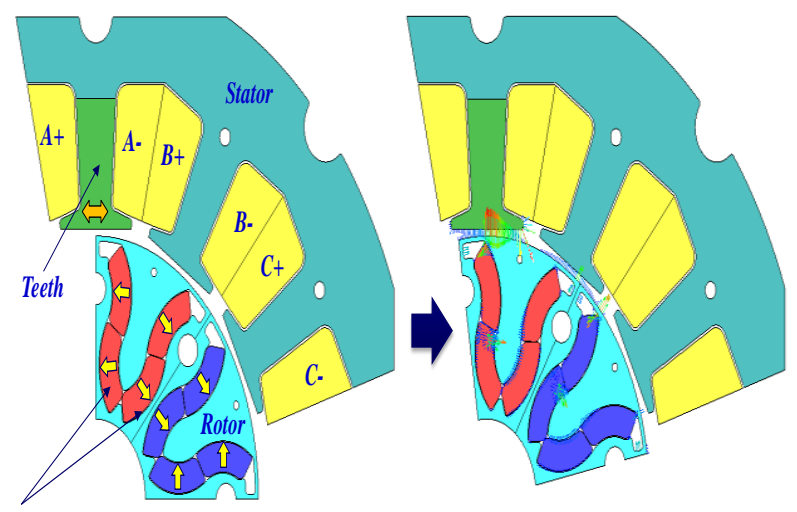

Ferrite magnet

Fig. 8: Nodal Forces Applied to Stator Teeth at the Load Condition.

\section{References}

[1] T.J.E Miller, Design of Brushless Permanent-Magnet Model, Clarendon press, Oxford, 1994

[2] Rukmi Dutta, et al., "Design and Analysis of an Interior Permanent Magnet(IPM) Machine With Very Wide Constant Power Operation Range”, IEEE Transactions Energy Conversion, March 2008, vol. 23 , no. 1 , pp. $25-33$

[3] Sung-il Kim, et al., "Characteristics comparison of conventional and modified spoke-type ferrite magnet for traction drives of lowspeed electric vehicles," IEEE Transactions on Industry Applications, November 2013, vol. 49, no. 6, pp. 2516-2523

[4] ung-Il Kim, et al., "Investigation and Experimental Verification of a Novel Spoke-Type Ferrite-Magnet Model for Electric-Vehicle Traction Drive Applications," IEEE Transactions on Industry Electronics, October 2014, vol. 61, no. 10, pp. 5763-5770

[5] H. J. Kim et al., "Structure of Concentrated-Flux-Type Interior Permanent-Magnet Synchronous Models Using Ferrite Permanent Magnets," IEEE Transactions on magnetics, November 2014, vol. 50, no. 11

[6] T. Ohnishi et al., " Optimal Design of Efficient IPM Model Using Finite Element Method," IEEE Transactions on magnetics, November 2000, vol. 36, no. 5, pp. 3537-3539

[7] M. M. Rahman et al., "Design and optimization of neodymium-free SPOKE-type model with segmented wing-shaped PM," IEEE Transactions on magnetics, February 2014, vol. 50, no. 2

[8] Francesco Parasiliti et al., "Finite-Element-Based Multiobjective Design Optimization Procedure of Interior Permanent Magnet Synchronous Model for Wide Constant-Power Region Operation", IEEE Transactions on Industry Electronics, June 2012, vol. 59, no. 6, pp. 2503-2514

[9] Liang Fang et al., "Study on High-Efficiency Performance in Interior Permanent-Magnet Synchronous Model With Double-layer PM Design", IEEE Transactions on magnetics, November 2008, vol. 44 , no. $11,99.4393-4396$

[10] Keun-young Yoon et al., "Optimal Design of a New Interior Permanent Magnet Model Using a Flared-Shape Arrangement of Ferrite Magnets," IEEE Transactions on magnetics, July 2016, vol. 52, no.7. 